\title{
KAJIAN DESAIN KANTOR UNTUK GENERASI MILENIAL DENGAN KONSEP PERKAMPUNGAN SEBAGAI PENGEMBANGAN DARI TIPOLOGI KANTOR
}

\author{
Felicia Melina Ismanto $^{1)}$, Nina Carina ${ }^{2)}$ \\ 1) Program Studi S1 Arsitektur, Fakultas Teknik, Universitas Tarumanagara, felicia.melina@yahoo.com \\ 2) Program Studi S1 Arsitektur, Fakultas Teknik, Universitas Tarumanagara, nincarin@gmail.com
}

\begin{abstract}
Abstrak
Seiring dengan perubahan zaman, perkembangan teknologi dan perubahan sikap manusia, bidang-bidang pekerjaan baru mulai berkembang, terutama bidang industri kreatif. Bidang ini semakin diminati oleh para Millennials yaitu orang yang lahir pada akhir tahun 1990 sampai awal tahun 2000. Jam kerja yang fleksibel dan sifat pekerjaan yang dinamis menjadi daya tarik utama dari bidang industri tersebut. Selain itu, modal awal yang tidak terlalu besar juga menjadi daya tarik tersendiri bagi para Millennials untuk membuka startup-startup industri kreatif baru. Untuk itu dibutuhkan ruang-ruang baru untuk bekerja yang sesuai dengan kebutuhan atau kebiasaan Millennials akan tetapi tetap memperhatikan standar-standar kebutuhan peraturan kantor. Penulis mengkaji dan menganalisis tentang perilaku generasi milenial didalam dunia kerja untuk menemukan tipologi baru, program serta desain arsitektural yang tepat. Program yang disajikan merupakan kebutuhan generasi millennial didalam bekerja yaitu sebuah wadah bagi para entrepreneur yang sedang berkembang agar menjadi entrepreneur yang baik dan mampu menyikapi dunia luar. Didalamnya, bangunan ini memiliki ruang-ruang sebagai wadah untuk berkomunitas bagi para pekerja, yang mana hal ini merupakan salah satu perilaku dari generasi millennial untuk berkembang menjadi lebih baik.
\end{abstract}

Kata kunci : Entrepreneur Muda; Generasi Milenial; Kantor; Komunitas; Tipologi

\begin{abstract}
Along with the changing times, technological developments and changes in human attitudes, new fields of work began to develop, especially in the field of creative industries. This field is increasingly in demand by Millennials, people born in the late 1990s until the beginning of 2000. Flexible working hours and the dynamic nature of work are the main attractions of the industry. Besides, the initial capital that is not too large is also the main attraction for Millennials to open new creative industry startups. For this reason, new spaces are needed to work by the needs or habits of Millennials, but still pay attention to the standards of office regulatory requirements. The author examines and analyzes the behavior of millennial generations in the world of work to find new typologies, programs, and appropriate architectural designs. The program presented is the need for the millennial generation to work, a forum for developing entrepreneurs to become good entrepreneurs and able to respond to the outside world. In it, this building has spaces as a place to the community for workers, which is one of the behaviors of the millennial generation to develop better.
\end{abstract}

Keywords : Community; Millenial Generation; Office; Typology; Young Entrepreneur

\section{PENDAHULUAN}

Generasi milenial merupakan generasi dengan tingkat produktivitas tertinggi dan merupakan salah satu tulang punggung penggerak perekonomian Indonesia. Kehadiran generasi ini menimbulkan terbukanya peluang lapangan pekerjaan baru di Indonesia, antara lain bisnis berbasis digital, entrepreneur, industri kreatif baru. Adanya pekerjaan baru sebagai freelancer dan startup-strartup harus sudah mulai direpresentasikan dalam bentuk tempat kerja yang sesuai dengan kebutuhan generasi milenial.

Generasi milenial memiliki perilaku di dalam bekerja yang berbeda dari generasi 
sebelumnya, salah satunya mengenai fleksibilitas dalam bekerja. Salah satunya adalah kemunculan tren tempat kerja yang sedang berkembang pesat dikalangan generasi milenial yaitu co-working space, dengan konsep fleksibilitas dalam bekerja. Co-working space cukup memenuhi syarat sebagai tempat kerja untuk para generasi millennial saat ini. Generasi milenial menuntut pengalaman ruang kerja yang baru, beserta fasilitas untuk berinovasi, berkreativitas, serta mengikuti perkembangan teknologi yang ada. Selain itu generasi milenial menginginkan konsep Work-Life Balance, dimana kehidupan selain bekerja, yaitu kehidupan pribadi mereka yang bersenang-senang, kesehatan mereka tidak ingin diganggu, karena bagi generasi milenial tempat kerja merupakan rumah kedua mereka. Didaerah Jakarta sangat berkembang pesat co-working space terutama pada bagian wilayah pusat dan selatan, dan umumnya co-working space terletak disekitar kawasan bisnis.

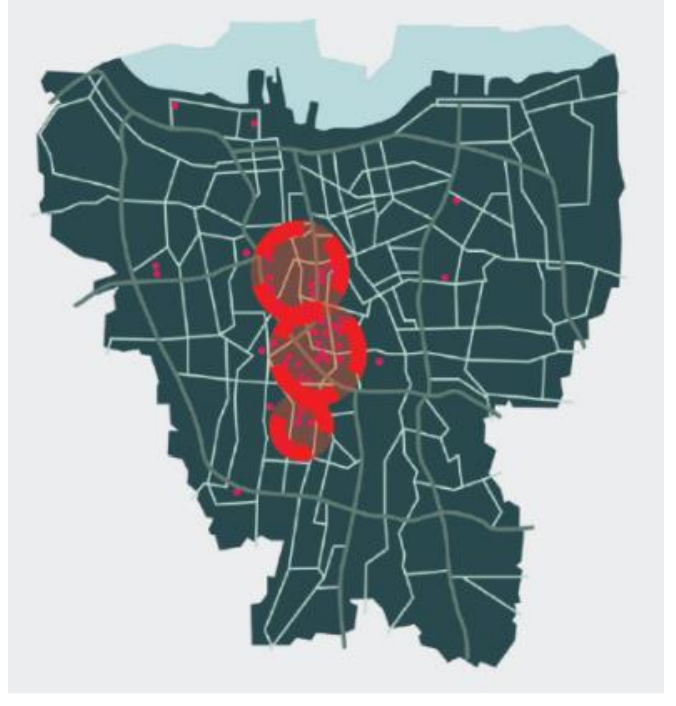

Gambar 1. Pemetaan Co-working Space Sumber: Penulis, 2019

Seiring berkembangnya jaman, struktur tempat bekerja menjadi berubah. Perubahan ini yang tadinya berhirarki vertical menjadi networking, yang tadinya individualis menjadi sosialis. Generasi milennial menekankan share, collaborate, communicate, technology, learn, find information, access technology, create content, collaboration, integrate dan flexibility. Proyek ini merupakan representasi dari perilaku generasi millennial yang diinginkan ketika mereka bekerja dengan cara mengembangkan tipologi kantor yang berkembang saat ini yaitu coworking space untuk membentuk sebuah tipologi baru dari kantor. Sebagai penunjang dari proyek ini maka ditambahkan program penunjang mereka untuk memenuhi konsep dari WorkLife Balance antara lain, napping station, gym, food space, refreshing area, play area dan public space untuk menciptakan ruang komunal dan terintergrasi antara proyek dan lingkungan sekitarnya. Proyek ini merupakan "a destination village for co-wokers" dimana workplace untuk generasi millennial adalah tempat untuk menciptakan dan menumbuhkan rasa kebersamaan, berguna dan terkoneksi dengan lingkungan sekitarnya dan tempat ini merupakan sebuah tempat tujuan mereka bekerja dan merupakan rumah kedua mereka.

\section{KAJIAN LITERATUR}

Generasi milenial merupakan generasi yang banyak diperbincangkan di berbagai bidang. Millenial yang juga dikenal sebagai Generasi Millenial atau Generasi Y adalah kelompok setelah generasi X dan sebelum generasi Z. Generasi ini lahir diantara tahun 1980 sampai 2000, jadi generasi millennial adalah generasi muda masa kini yang saat ini berusia dikisaran 15-34 tahun. Generasi ini merupakan generasi dengan jumlah populasi terbesar yang ada di Indonesia. 


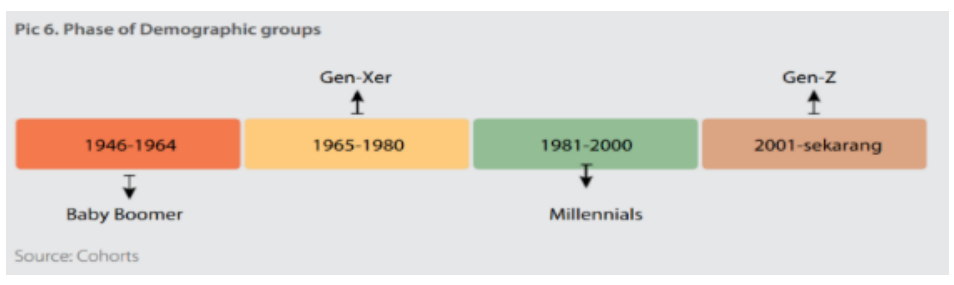

Gambar 2. Fase Kelompok Demografi

Sumber: INDONESIA 2020: The Urban Middle - Class Millennials, 2016

Ditahun 2020 generasi millennial berada pada rentang usia $20-40$ tahun. Usia ini tersebut adalah usia produktif yang akan menjadi tulang punggung perekonomian Indonesia. Menurut dara Badan Pusat Statistik (BPS), jumlah penduduk Indonesia usia 20 - 40 tahun di tahun 2020 diduga berjumlah 83 juta jiwa atau $34 \%$ dari total penduduk Indonesia yang mencapai 271 juta jiwa. Proporsi ini lebih besar dari proporsi generasi $X$ yang hanya $20 \%$ maupun generasi baby boomer yang hanya $13 \%$ saja.

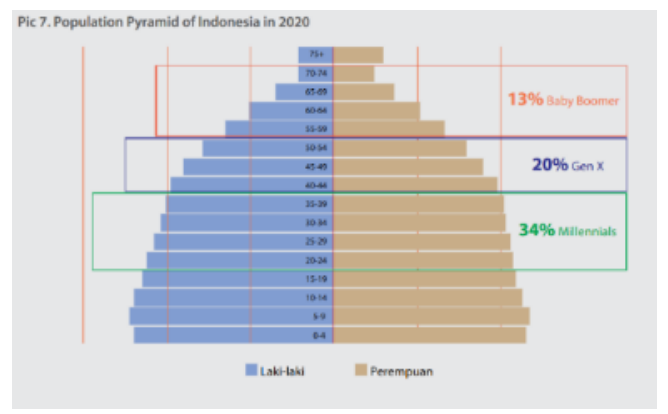

Gambar 3. Piramida populasi di Indonesia tahun 2020

Sumber: INDONESIA 2020 : The Urban Middle - Class Millennials, 2016

Generasi Milenial identik dengan karya yang inovatif dan kreatif didalam bekerja serta merupakan salah satu penggerak terbesar era ekonomi kreatif. Melihat dari keadaan lingkungannya, generasi milenial adalah generasi yang terpapar kemudahan teknologi informasi dan komunikasi. William Deresiewics (2011) menyebut generasi milenial sebagai generation sell. Tentunya ini turut dipengaruhi berbagai kemudahan tersebut. Bahkan cultural hero dari generasi ini adalah entrepreneur. Maka dari itu, jenis pekerjaan generasi milenial kebanyakan mengarah ke sektor industri kreatif. Terdapat 2 kategori di dalam sektor kreatifitas, yaitu industri kreatif yang bergerak di bidang teknologi, dan industri kreatif yang bergerak di bidang seni.

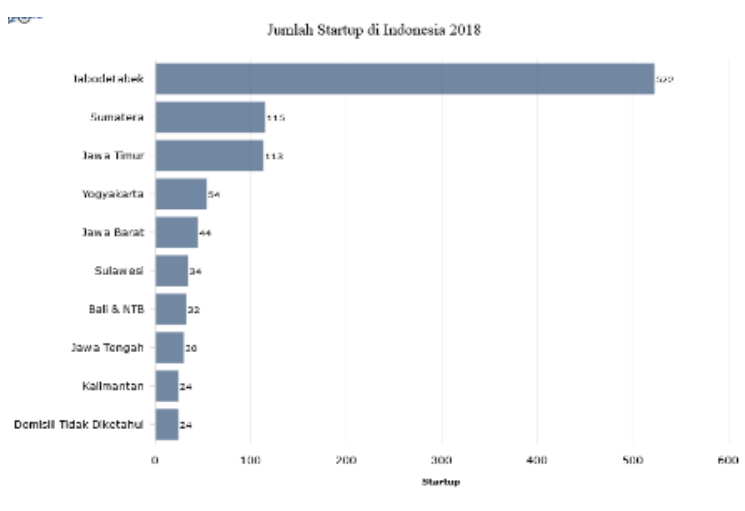

Gambar 4. Konstribusi PDB Ekonomi Kreatif

Sumber: Badan Pusat Statistik Kota Administrasi Jakarta Barat, 2018 
Menurut McKinsey Globe Institute, terdapat perubahan kategori pada tahun 2030 yaitu revolusi Industri 4.0. Pada tahun 2027, diperkirakan mayoritas pekerjaan akan berbentuk freelance dan perkembangan teknologi akan terus terjadi. Untuk itu dibutuhkan skill guna menghadapi situasi tersebut, seperti people management, cognitive flexibility, critical thinking, dan complex problem solving. Pendapatan serta tenaga kerja di bidang ekonomi kreatif di Indonesia diprediksikan akan terus bertambah. Sehingga sebuah arsitektur diperlukan untuk menyediakan fasilitas yang layak dan nyaman sesuai kebutuhan para pekerja generasi milenial ini.

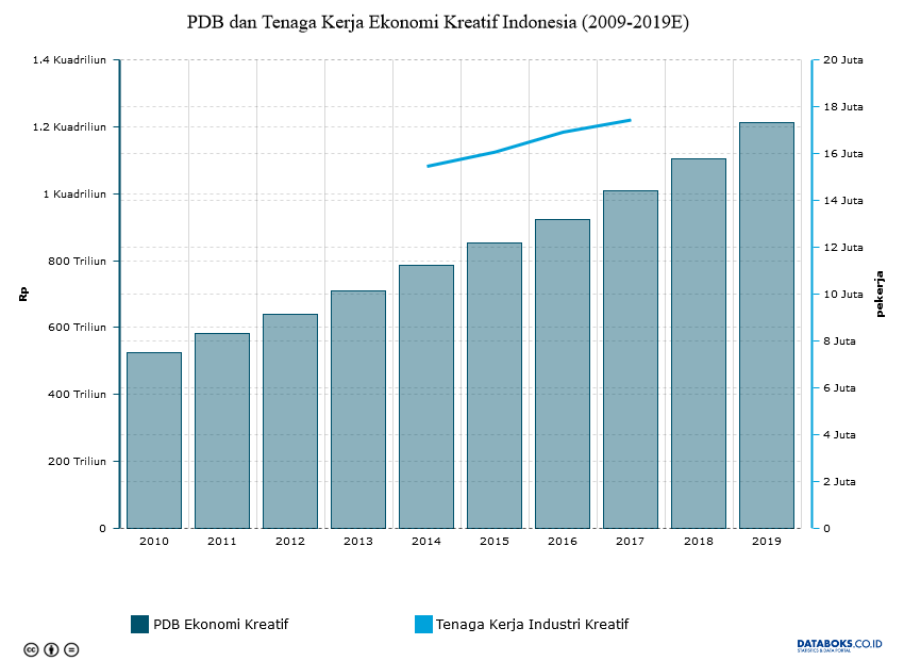

Gambar 5. PDB dan Tenaga Kerja Ekonomi Kreatif Indonesia Sumber: Badan Pusat Statistik Kota Administrasi Jakarta Barat, 2019

Menurut survey PWC's didalam risetnya "Millenials at work", pada tahun 2020, 50\% tenaga kerja merupakan generasi millennial dan di tahun 2025 akan mencapai 75\%. Tentu saja jumlah ini berkembang dengan pesat, karena generasi milenial merupakan generasi yang produktif. Hal ini dipengaruhi beberapa faktor, salah satunya adanya perilaku mereka ketika bekerja yang berbeda dari generasi sebelumnya.

Terdapat perbedaan paradigma yang mencolok antara Generasi $X$ dan Generasi Milenial terkait dunia kerja. Generasi $X$ memandang ukuran sukses di dunia kerja adalah ketika mereka sukses meniti karir dari bawah sampai ke puncak posisi di perusahaan yang sama, loyalitas pada perusahaan adalah salah satu ukuran kunci sukses. Bagi generasi Millenial ukuran sukses di dunia kerja adalah ketika mereka bisa pindah-pindah kerja dari perusahaan ke perusahaan lain.

Sebuah studi yang dilakukan oleh UXC Professional Solution, menunjukkan kelebihan generasi Millenial ditempat kerja dibanding generasi sebelumnya adalah terkait kemampuan menggunakan teknologi dan adaptasinya. Kelompok urban middle-class millennials adalah kelompok dengan sikap creative dan confidence menurut VISA (2012), generasi ini juga memiliki karakter ambisius terkait capaian dan cita-cita. Karakter tersebut menimbulkan konsekuensi tersendiri bagi dunia kerja dan entrepreneurship.

Sosialisme, kolaborasi, konektivitas dan fleksibel merupakan sifat-sifat yang erat hubungannya dengan generasi ini. Sehingga dalam struktur tempat kerjapun berubah, yaitu timbulnya workplace structure yang tadinya my workplace menjadi our workspace, yang mana kantor tempat mereka bekerja sekarang yang lebih mengarah untuk menciptakan komunitas yang menjadi kolaborasi dan fleksibel, salah satunya berubah menjadi co-working space.

Co working space merupakan bentuk baru tipologi perkantoran. Berawal dari kantor sewa yang mengadaptasi perkembangan cara bekerja yang berubah menjadi semakin fleksibel. Didasarkan pada pola hubungan antar pekerja yang terus mengalami evolusi dari masa ke 
masa. Pada saat ini pola kerja tim memberikan ruang bagi semua pekerja dalam satu tim untuk bisa andil dalam pengerjaan proyek leader yang memiliki peran untuk mengayomi sekaligus menjadi mengambil keputusan akhir. Pola - pola kerja tersebut berkembang di mana pekerja tidak lagi harus bernaung di dalam suatu pekerjaan atau tim yang sama terus menerus, melainkan berdiri di atas nama pribadi dan tidak terikat dalam suatu instansi.

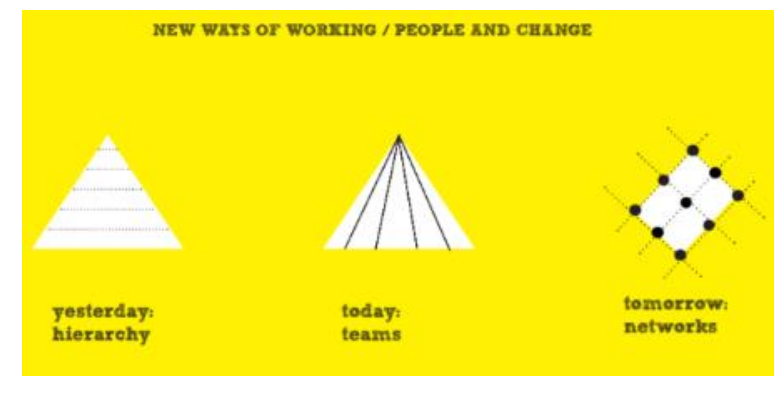

Gambar 6. Konsep Co-Working Space

Sumber: Bergin, 2014

Co-working Space menawarkan nilai tambah berupa network bagi sesama freelancer. Coworking Space pada dasarnya adalah penyewaan meja kerja di ruang terbuka untuk waktu yang fleksibel. Sebagai bentuk baru dari rental office, ruang tersebut bersifat berbagi pakai dengan orang lain untuk menekan biaya sewa. Pengguna datang dari latar belakang yang berbeda beda seperti pengusaha, asosiasi, seniman, mahasiswa, peneliti sebagai "rekan kerja". Perbedaan latar belakang menimbulkan interaksi yang bersifat dinamis karena setiap orang memiliki kelebihan masing-masing dalam pembahasan proyek pekerjaan sehingga hasilnya dapat lebih maksimal.

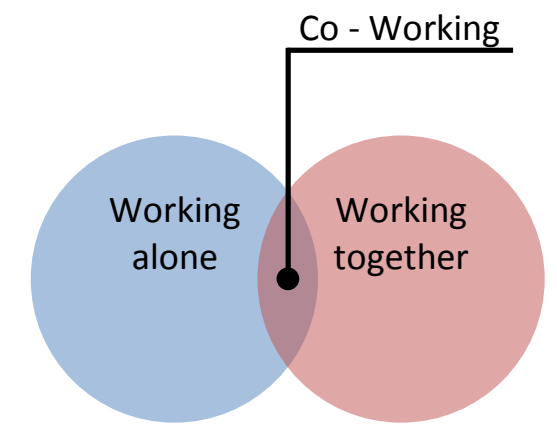

Gambar 7. Konsep Co-Working Space

Sumber : Maulana, 2018

Co-working space saat ini merupakan sebuah trend tempat kerja bagi generasi millennial, namun co-working space ini memiliki beberapa kelemahan yaitu pada konsep desain open plannya. Open plan ini mempengaruhi privasi antar pengguna co-working space ini, faktorfaktor lainnya adalah sibuk dan bising.

Terdapat beberapa kata yang merujuk pada generasi milenial, seperti liberal, kebebasan, fleksibilitas, networking, pemberdayaan, multi-tasking, kewirausahaan. Kewirausaahaan disini terkait dengan pola pikir generasi millennial ini dalam memulai sebuah perusahaan. Pola pikir berkewirausahaan membantu mereka menemukan nilai dalam pekerjaan mereka dan berusaha sebaik mungkin, karena menggambarkan diri mereka sebagai pemilik perusahaan.

Struktur organisasi yang hirarki dengan manajemen top-down sudah bukan lagi menjadi bagian yang penting. Milenial memiliki konsep baru dalam berorganisasi, yaitu struktur tim yang bekerja dalam networking, jaringan struktur yang kolaboratif ini lebih banyak menghasilkan inovasi, kreatifitas dalam bekerja. Prinsip kolaboratif ini dapat memelihara nilai- 
nilai dan budaya bersama, transparansi, akses mudah untuk mencari informasi, menghargai ketrampilan dan kemampuan individu ataupun tim. Karena itu dengan menciptakan workspace bagi generasi millennial ini dapat menjadi identitas mereka bekerja yang didasari kebutuhan mereka serta dengan memfasilitasi penunjang yang lain untuk mereka, sehingga menyebabkan peluang mereka mendapatkan lebih banyak jaringan dan menjadikan dalam bekerja lebih efektif, lebih berkolaborasi, dan lebih inovatif.

Didalam bekerja generasi millennial mengutamakan konsep work life balance, antara bekerja dan kehidupan pribadi mereka harus seimbang. Generasi millennial merupakan generasi yang tingkat fleksibilitasnya sangat tinggi, mereka bisa kapan saja untuk bekerja, sehingga future workplace akan menjadi 24 jam, tidak menutup kemungkinan adanya aktivitas pada malam hari. Selain itu penerapan teknologi yang up to date menjadikan pekerjaan lebih efisien dan efektif.

\section{METODE}

Tugas akhir ini menggunakan beberapa langkah pendataan guna mendapat informasi yang matang untuk melakukan perancangan, yaitu :

a. Metode pengumpulan data melalui survei terhadap co-working space, pengamatan lokasi tapak, dan wawancara beberapa narasumber di co-working space maupun sekitar tapak.

b. Metode Kajian teori/ literatur mengenai kantor, teori tipologi kantor, teori co-working space, teori mengenai generasi milenial beserta perilakunya, dan aspek regulasi serta peraturan.

c. Metode pemahaman objek perancangan melalui kajian studi objek, kajian analisa tapak dan lingkungannya.

Metode Desain Perancangan

a. Metode desain perancangan menggunakan pendekatan theory proxemic.

Proxemic theory oleh Edward T. Hall digunakan sebagai metode perancangan proyek ini. Setelah dianalisa dan digolongkan mendapatkan hasil berupa beberapa tipe - tipe ruang yang nantinya akan diterapkan kedalam desain perancangan.

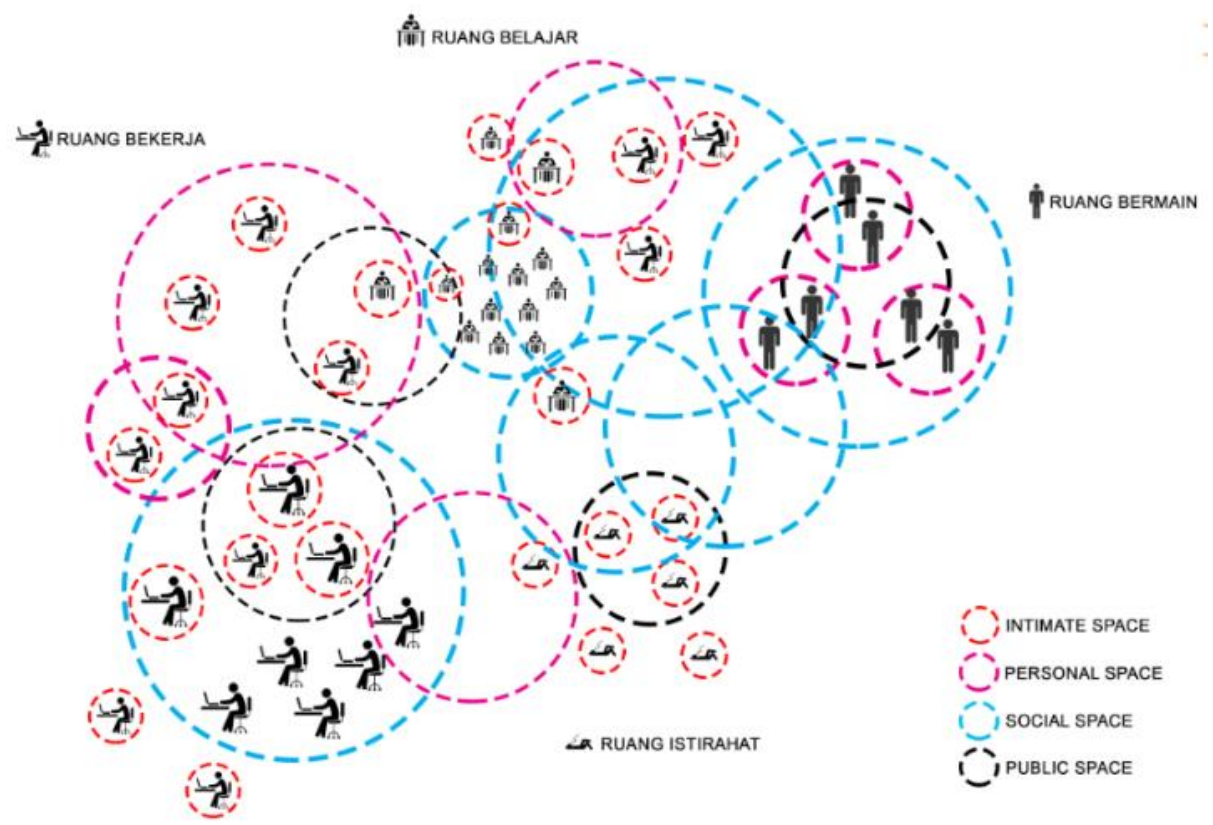

Gambar 8. Diagram Proxemic Theory

Sumber : Penulis, 2019 
b. Desain perancangan mempertimbangkan standardisasi dan kebutuhan program sesuai dengan perilaku generasi millenial.

Dalam menetapkan luasan ruang dan kebutuhan mempertimbangkan standard dan peraturan yang ada. Begitupula dengan modul pod pada kantor ini mempertimbangan kebutuhan ruang dari pekerja yang mana dalam proyek ini standard untuk orang bekerja merupakan $6 \mathrm{~m}^{2}$ /orang, sehingga ditetapkan modul pod yaitu $24 \mathrm{~m}^{2}$ untuk 4 orang.

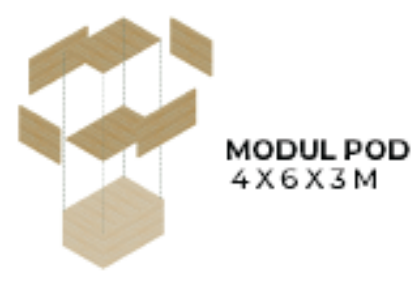

Gambar 9. Modul Pod

Sumber : Penulis, 2019

\section{DISKUSI DAN HASIL}

Dalam proyek yang bertemakan Dear Millenials, Type and Behaviour ini. Tujuan dari penulis adalah menciptakan sebuah tipologi baru dari tipologi yang telah ada sebelumnya berdasarkan perilaku dari generasi milenial. Tapak yang penulis ambil berada di kawasan Puri Kembangan. Berdasarkan pemerintah, kawasan ini merupakan kawasan yang direncanakan dan dikembangkan menjadi sentra primer barat sebagai kawasan industri ekonomi kreatif di wilayah Jakarta Barat.

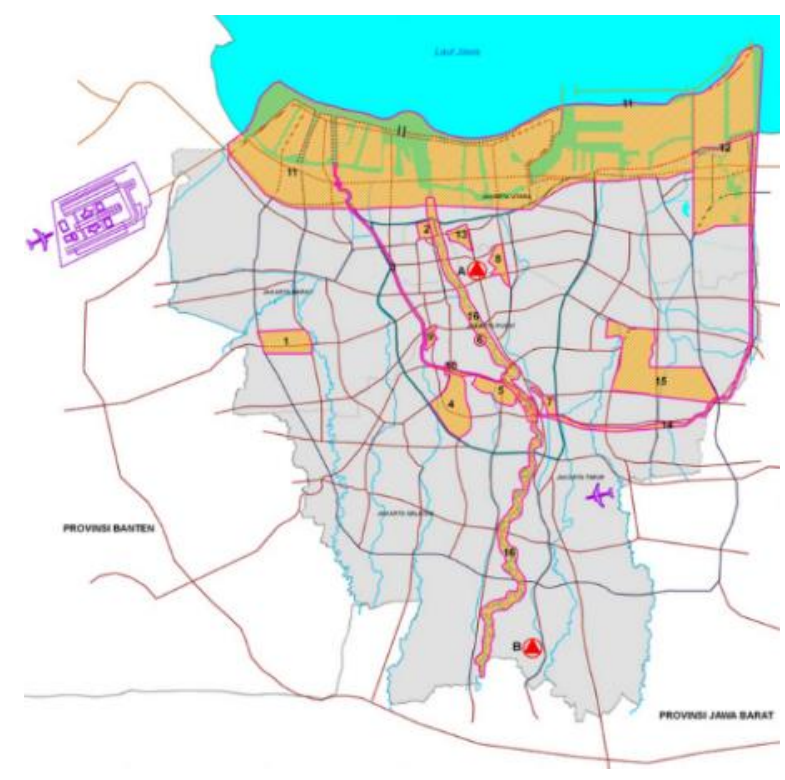

Gambar 10. Diagram Analisa Tapak

Sumber: Peta Rencana Jakarta 2030

Dari tapak tersebut dianalisa mengenai potensi-potensi yang ada disekitar tapak, dimulai dari view, sirkulasi jalan, sirkulasi entrance, integrasi dengan ruang luar, potensi pedestrian dari transportasi publik, kondisi tapak sekitar terkait dari suasna dan fasilitas sekitar tapak. 


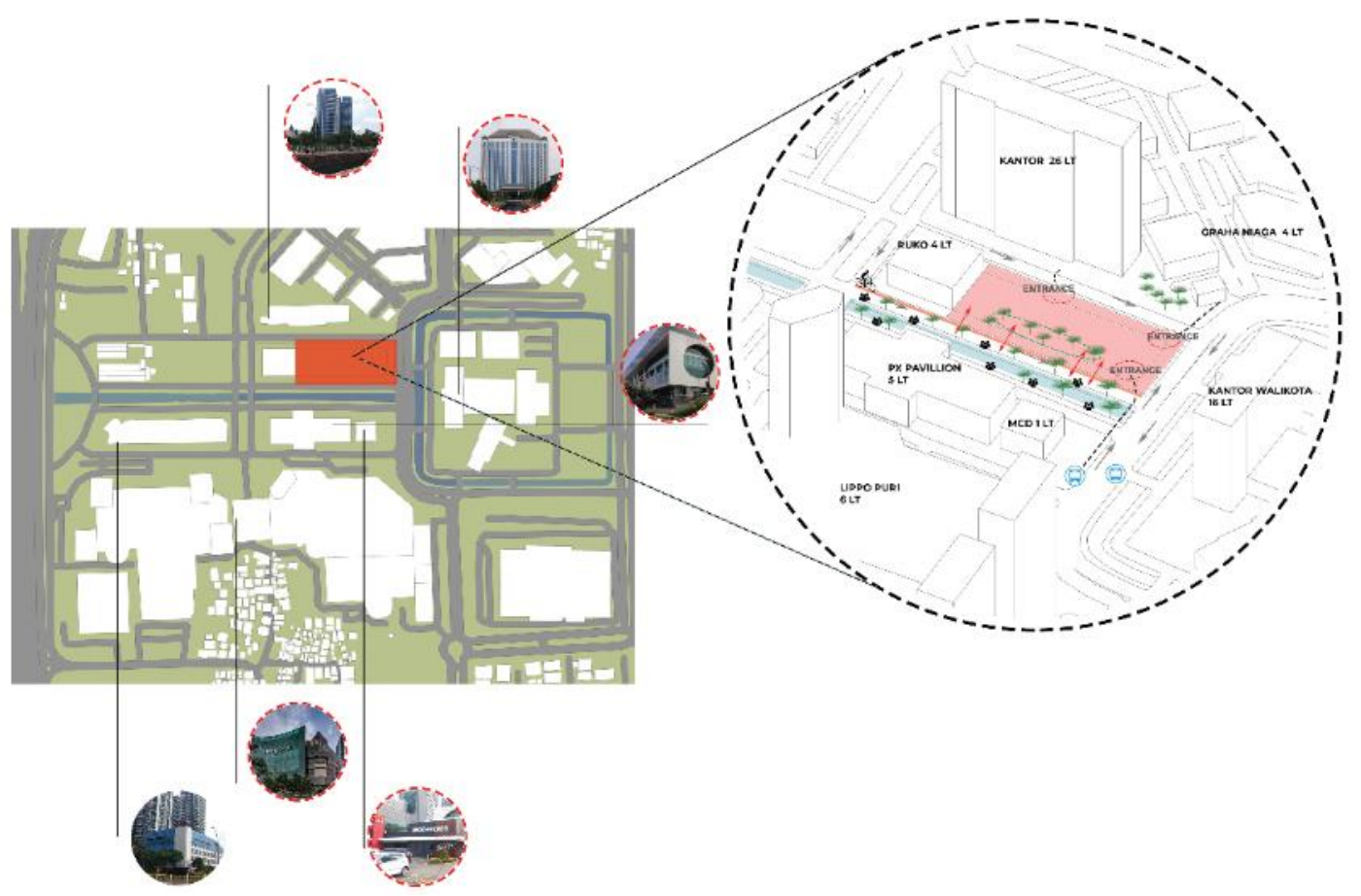

Gambar 11. Analisa Tapak

Sumber : Penulis, 2019

Selanjutnya analisa tapak tersebut menghasilkan suatu proses gubahan massa dengan memikirkan efisien dan efektif dari gubahan massa tersebut. Proses gubahan massa sendiri terdiri dari 5 tahap dan menghasilkan gubahan massa yang sangat sederhana. Dikarenakan proyek ini memiliki tapak yang sangat panjang dan dikelilingi oleh 3 jalan utama, sehingga sulit untuk melakukan permainan massa ditapak ini. Dari hal tersebut, memunculkan ide untuk mengeksteriorkan interior proyek ini dengan memberikan konsep yang dibutuhkan generasi milenial untuk tempat kerja mereka.

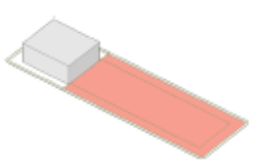

SITE

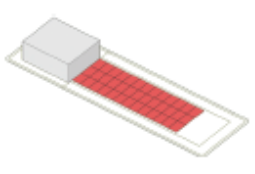

MODUL

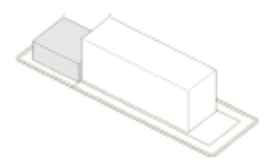

EXTRUDE

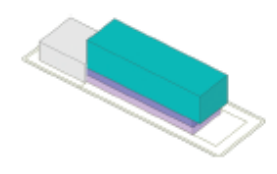

ZONING

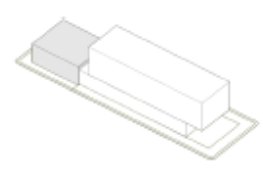

SETBACK

Gambar 12. Skema Desain

Sumber : Penulis, 2019

Menurut Christoper Allen, Head of workplace consulting Morgan Lovell, bahwa sebuah tempat kerja akan menjadi "a destination village for co-workers" dimana tempat kerja akan menimbulkan rasa kekeluargaan, rasa komunitas yang tinggi, dan terkoneksi dengan lingkungannya. Dengan adanya rasa komunitas yang tinggi tersebut, penulis coba mengkaji arti sebuah komunitas tersebut, dan menurut MVRDV, sebuah komunitas yang sangat kuat berada di sebuah perkampungan, dimana komunitas tersebut akan terjadi secara alamiah. Dari hal tersebutlah, penulis menetapkan proyek ini dengan judul "Creative Office Pod for Young Entrepreneur". Diharapkan dapat menjadi sebuah tipologi baru bagi sebuah kantor untuk para generasi milenial. Dalam merancang dan menggunakan metode proxemic theory dihasilkan sebuah tipe-tipe ruang sebagai dasar untuk menyusun pod-pod yang ada. 


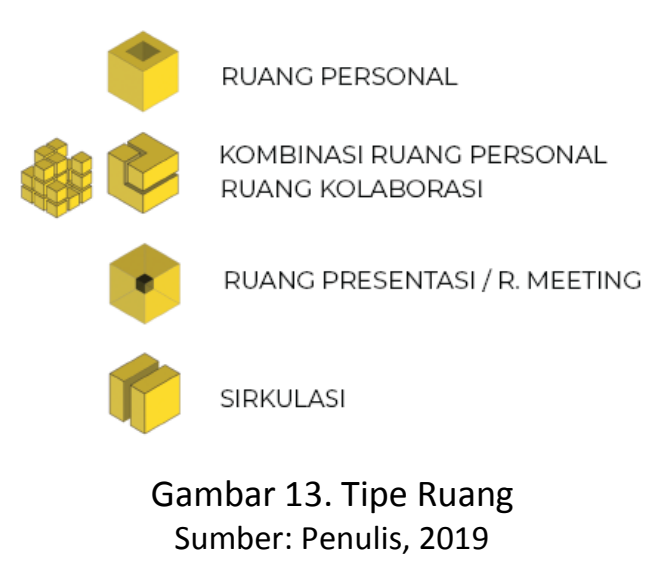

Modul Pod didapatkan dari standard kebutuhan ruang yang diperlukan oleh pekerja yaitu $6 \mathrm{~m} 2 /$ orang. Terdapat 56 tipe pod yang membentuk kantor ini dengan jumlah 145 pod yang terdiri dari 67 pod single, 24 pod double, dan 54 pod kombinasi secara vertikal dan horisontal. Rasio dari jumlah pod tersebut didapatkan melalui analisa rasio jumlah ruang sesuai dengan kapasitas pengguna per ruangnya didalam studi preseden beberapa co-working space yang terdapat di Jakarta.

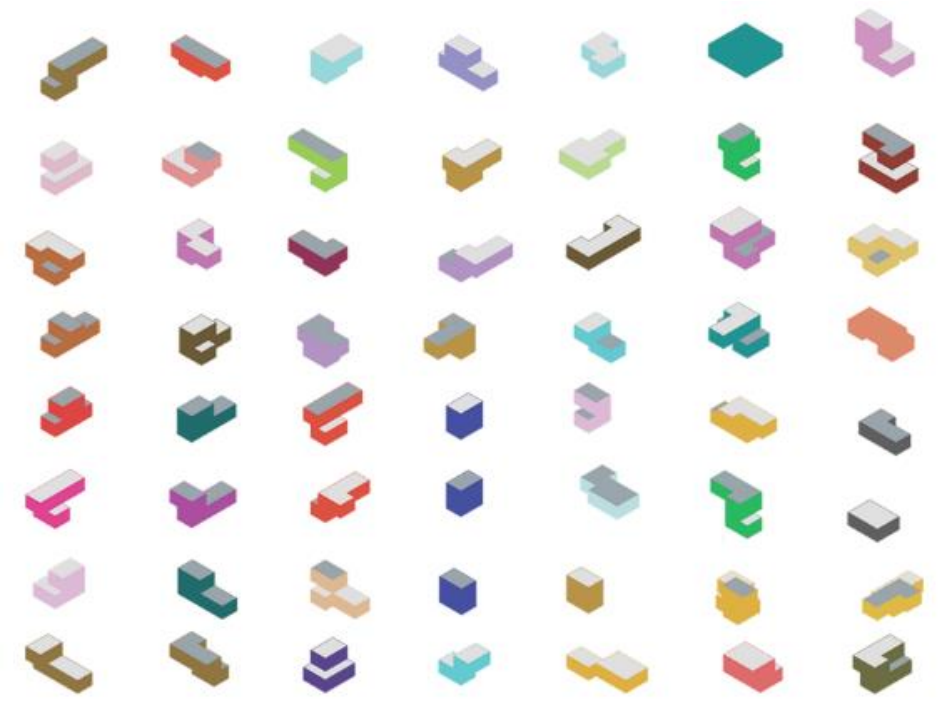

Gambar 14. Tipe POD

Sumber: Penulis, 2019

Kemudian pod-pod tesebut disusun secara acak dengan tetap memperhatikan luasan kebutuhan ruang, jarak sirkulasi terhadap tangga kebakaran, lebar sirkulasi, dan lainnya. Penyusunan secara acak ini dilakukan untuk mendapatkan konsep village itu sendiri, karena didalam village akan menciptakan suasana yang lebih homey dimana yang tinggal disana akan memiliki rasa kepemilikan terhadap rumahnya yang tinggi sehingga pengguna akan merasa nyaman. Sama halnya konsep ini diterapkan kedalam kantor ini untuk memberikan kesan nyaman saat bekerja dikantor ini. 


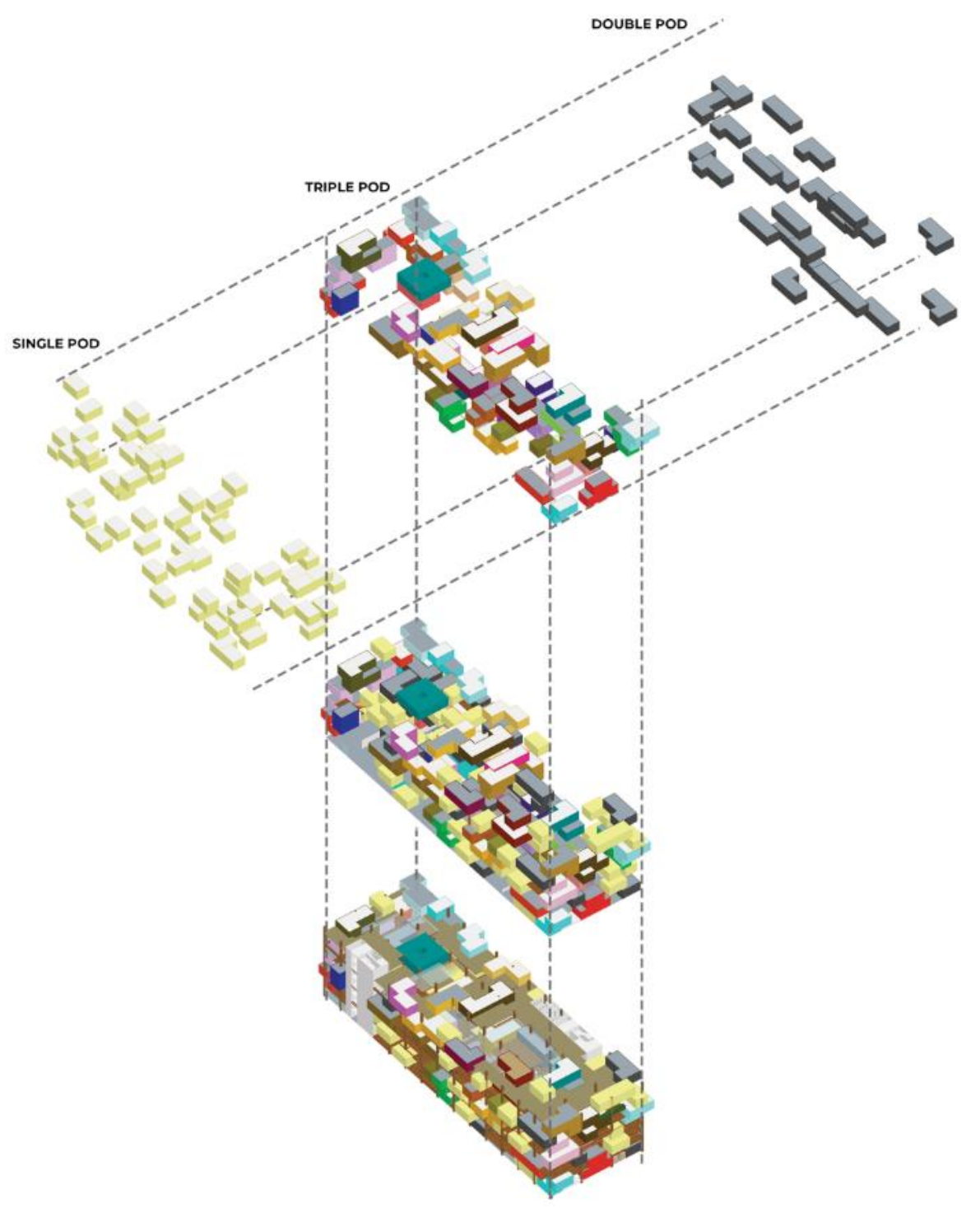

Gambar 15. Diagram Office POD Village

Sumber: Penulis, 2019

Penyusunan pod-pod tersebut secara acak akan menghasilkan ruang-ruang besar yang mana ruang besar ini dijadikan sebagai tempat collaborative space, pantry bersama, play room, event space. Selain menghasilkan ruang-ruang besar, adapula ruang-ruang kecil yang dimanfaatkan untuk meeting area, ruang baca, dan napping pod. Area kantor ini terletak pada lantai 3 sampai lantai 6 yang berupa rooftop dan lebih dikhususkan untuk area event, ruang meditasi, dan communal space. Sedangkan program pada lantai 1 dan 2 lebih dikhususkan untuk makerspace. Makerspace didalam bangunan ini terbagi menjadi dua bagian yaitu Food Makerspace pada lantai 1, dimana para startup pada industri kuliner ini dapat langsung memproduksi dan menjualnya di satu tempat yang mana konsumennya sebagian besar merupakan pengguna kantor yang ada diatas. Hal ini diterapkan untuk mempercepat feedback bagi para stratup itu sendiri. Sama halnya dilantai 2 terdapat Fashion Makerspace, galeri, ruang multifungsi yang dapat digunakan sebagai galeri ataupun eventspace. Pemisahan menjadi 2 bagian antara Makerspace dan kantor bertujuan untuk memberikan suasana yang tidak terlalu chaos dari segi aktivitas pengguna, kebisingan, dan juga privasi dalam skala besar dari program ruang utama. 


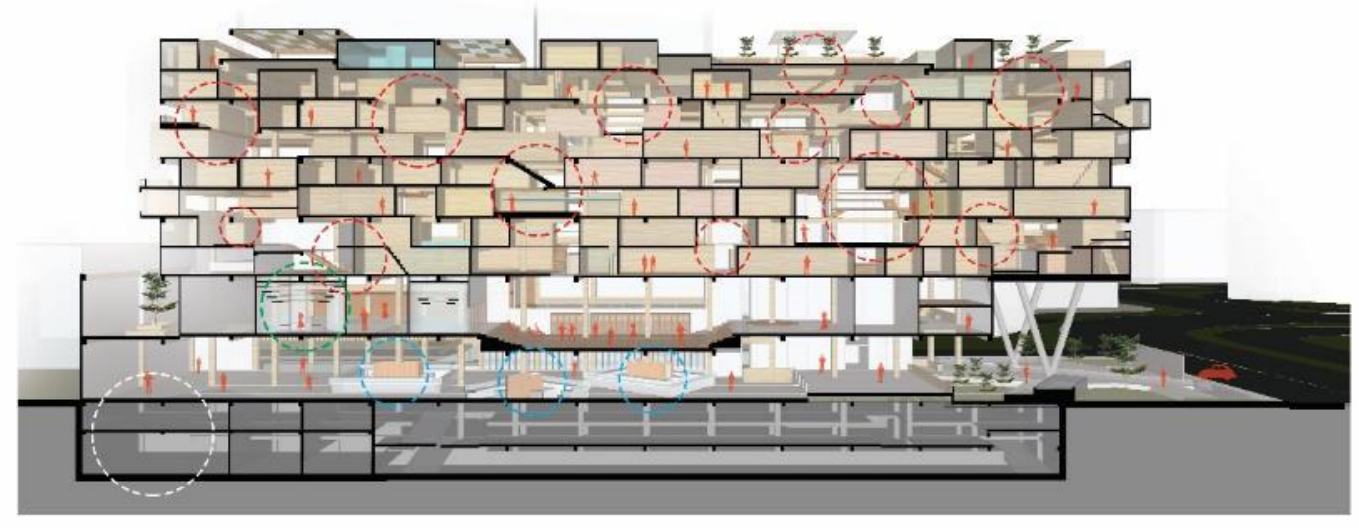

Gambar 16. Potongan Perspektif Sumber: Penulis, 2019

Pemilihan bahan material didapat dari hasil analisa penggunaan material dikawasan Puri Kembangan, dimana di kawasan ini menggunakan material seperti beton dan kaca yang lebih mengarah ke modern futuristik. Proyek perancangan ini menggunakan material utama yaitu Cross Laminated Timber. Untuk menciptakan bangunan yang ikonik dikawasan ini salah satunya melalui penggunaan material yang berbeda dari lingkungan sekitarnya. Dari hasil analisa, kawasan ini kurang memiliki wajah ruang hijau kota, sehingga material kayu ini dipilih untuk memberikan kesan yang lebih natural dan green untuk memberikan sumbangsih terhadap wajah ruang hijau kota dikawasan ini. Dari kajian yang telah penulis dapatkan, dapat disimpulkan bahwa material ini sangat cocok untuk digunakan pada bangunan ini, dan memiliki banyak keuntungan yang dimiliki bahan baku material ini. Adapula material pendukung yang digunakan adalah berupa beton, kayu, kaca, dan baja untuk mendapatkan kesan natural tetapi tetap modern untuk menyelaraskan dengan lingkungan sekitar.

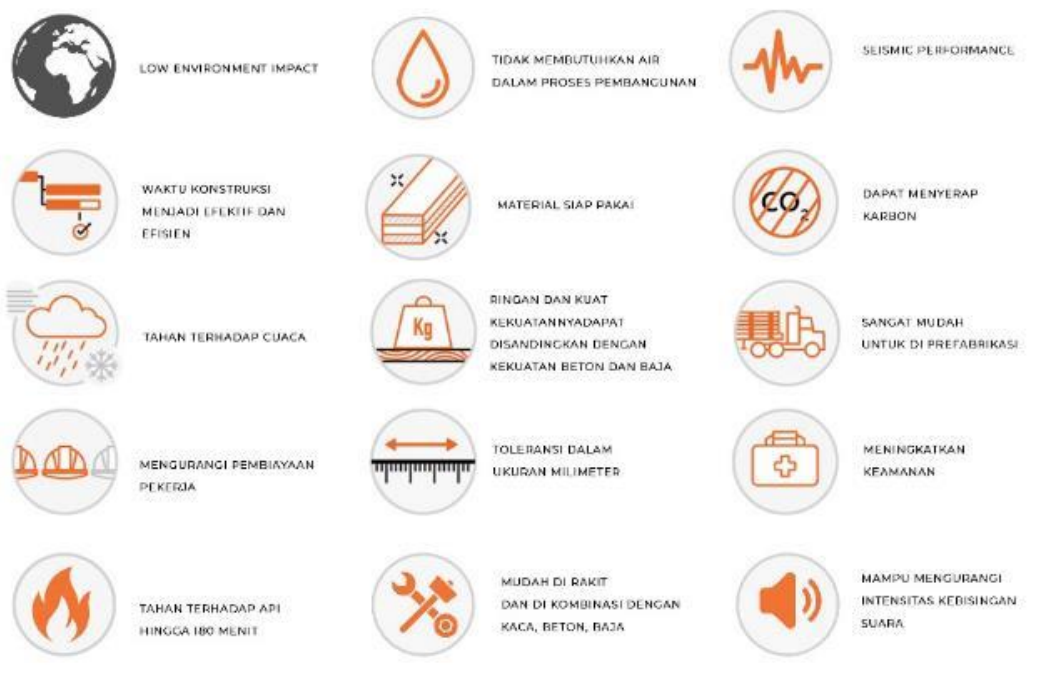

Gambar 17. Keuntungan Material CLT

Sumber: Hasil Olahan Penulis dan Solid Timber Construction, 2015

Secara keselurahan bangunan ini akan menjadi sebuah ikon dikawasan tersebut dari segi material yang berbeda dengan lingkungan sekitar kemudian dari segi massa bangunan juga tergolong merupakan wajah baru di kawasan Puri Kembangan ini. Sehingga akan menjadi daya tarik tersendiri bagi pengguna yang merupakan generasi milenial dan kawasan itu sendiri. 


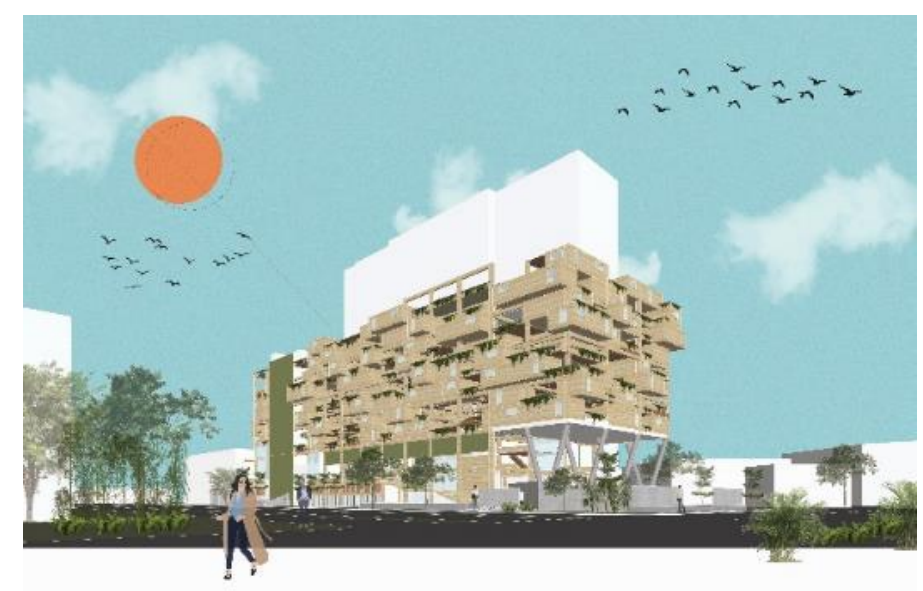

Gambar 18. Perspektif Eksterior Sumber: Penulis, 2019

Suasana sebuah village sangat ingin ditonjolkan didalam proyek ini, karena di dalam village mengandung komunitas yang sangat kuat, sehingga menjadikan pengguna proyek ini yaitu pekerja menimbulkan kekeluargaan, saling berbagi, saling berkomunikasi, belajar, mencari informasi, menciptakan konten, rasa memiliki, kolaborasi, inovasi yang lebih, kerjasama team, dan lebih sosialis khususnya dalam dunia kerja.
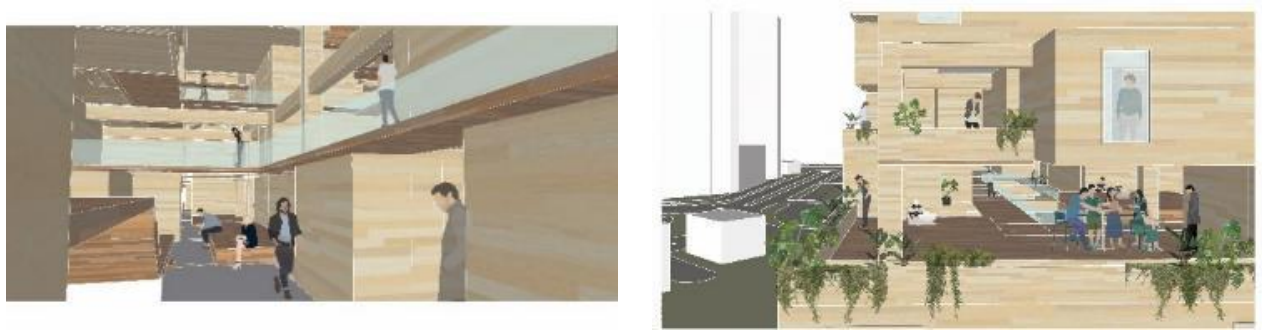

Gambar 19. Interior Creative Office Pod Sumber: Penulis, 2019

\section{KESIMPULAN DAN SARAN}

\section{Kesimpulan}

Berdasarkan hasil studi dan analisis yang telah dilakukan selama perancangan proyek Kantor Kreatif bagi Entrepreneur Muda, maka dapat ditarik kesimpulan. Generasi Millenial merupakan generasi yang tingkat produktivitasnya tinggi. Dengan didasari pekerjaan millennial yang lebih mengarah ke entrepreneurship, bidang industri kreatif, dan bisnis berbasis digital serta kehidupan yang dipengaruhi oleh teknologi, perilaku mereka terhadap bekerja seperti menginginkan work life balance dalam hidup mereka maka tipologi sebuah tempat kerja akan berubah, bukan lagi mementingkan sebuah hirarki namun mereka akan lebih kearah networking.

Proyek Creative Office Pod ini merupakan tempat tujuan para entrepreneur yang masih pada tahap berkembang untuk dapat bekerja, menemukan dan membentuk komunitas, sehingga dapat berguna dan terkoneksi pada lingkungan sekitar mereka, dan dapat menjadi startup yang lebih mandiri nantinya. Proyek ini memberikan fasilitas untuk mereka bekerja, berkarya, berinovasi, serta mendapatkan feedback dan health balance. Selain itu untuk mencapai konsep dalam bekerja yang diinginkan generasi millennial yaitu Work Life Balance, sehingga Creative Office Pod ini juga merupakan sebagai "rumah" kedua mereka, dimana mereka merasa nyaman saat bekerja, dan dengan berkembangnya jaman kegiatan kerja juga dipengaruhi oleh teknologi. Oleh karena itu diharapkan proyek ini akan menjadi sebuah tipologi baru yang merupakan pengembangan dari sebelumnya yang dilandasi dari perilaku 
generasi milenial serta menjadi sebuah ikon baru di kawasan Jakarta Barat khususnya Puri Kembangan yang memiliki lokasi strategis, akan ada perkembangan CBD di kawasan tersebut dan dekat dengan pusat pemerintahan Jakata Barat.

\section{Saran}

Proyek perancangan ini tentunya masih dapat dikembangkan lebih lanjut, antara lain penggunaan pola-pola tertentu yang masih perlu ditinjau kembali dalam penyusunan modul dari pod itu sendiri.

\section{REFERENSI}

Ali, H., Purwandi, L. (2016). INDONESIA 2020: The Urban Middle-Class Millennials. Jakarta, Alvara Research Center.

Alexander, H. (2014). Tiga Hal yang Bikin Jakarta Barat Berpotensi Jadi Pusat Bisnis, Kompas, diunduh $10 \quad$ Januari 2019, https://properti.kompas.com/read/2014/09/03/190905221/Tiga.Hal.yang.Bikin.Jakarta.Bar at.Berpotensi.Jadi.Pusat.Bisnis.

Eko, S. (2015). Panduan SDGs. Jakarta, International NGO forum on Indonesian Development. Ergin, D. (2014). How to create a co-working space handbook. Politecnico di Milano.

Fox, A. (2017). How Millenials Are Reshaping Workplace Culture And Business Environs, Element 7 Digitals, diunduh 9 Januari 2019, https://element7digital.com.au/blog/howmillennials-are-reshaping-workplace-culture-and-business-environs

IImu Ekonomi ID. (2016). IImu Ekonomi ID. Diunduh 10 Januari 2019, https://www.ilmuekonomi-id.com/2016/10/pengertian-dan-tujuan-sdgs-sustainable-development-goals.html

Jahja, E. (2018), " New CBD” Jakarta Itu Kini Berada Di Koridor Puri \& Lingkar Luar Barat, Property Inside, diunduh 9 Januari 2019, https://www.propertyinside.id/2018/03/26/newcbd-jakarta-ciputra-international/

Maulana, R. (2018). Peluang Co-working Space di Indonesia pada 2018 Masih Terbuka Lebar, Technasia Id, diunduh 9 Januari 2019, https://id.techinasia.com/peluang-coworking-spacelokal-2018

PwC commissioned Opinium Research. (2016). Millenials at work, reshaping workplace. Trianda, A. (2012), Arsitektur Perilaku, diunduh 9 Januari 2019 http://adindatrianda.blogspot.com/2012/04/normal-0-false-false-false-en-us-x-none.html

United Cities and Local Governments. (2015). Tujuan Pembangunan Berkelanjutan yang perlu diketahui oleh Pemerintah Daerah. 
